\section{Commentary: A novel surgical technique for scimitar syndrome: A new standard or a long run for a short slide?}

\section{Paul J. Chai, MD}

In this issue of JTCVS Techniques, Geggel and colleagues ${ }^{1}$ from Boston describe a new technique for surgical repair of scimitar syndrome. They report on a novel multipatch surgical technique for scimitar syndrome and compare results and outcomes with the standard technique performed before the use of the new technique. Twenty-two patients from 2011 to 2018 are included in the study. The previous technique involved baffling or reimplantation and was associated with a $50 \%$ incidence of postoperative pulmonary vein obstruction. The new technique introduces the idea of resection of the atrial septum and complete removal of the muscular limbus (exiting the heart as a result). The posterior wall of the left atrium is then reconnected to the previous posterior wall of the right atrial edge "pulling down the left atrium towards the scimitar vein" (as described by the authors). The scimitar vein to atrial connection is enlarged with a V-shaped incision (into scimitar vein and lateral wall of right atrium) and then patched with pulmonary homograft tissue. The atrial septum is then septated (baffling scimitar vein to left atrium) with pericardium. A final patch of pericardium is then used to augment the right atrium/inferior vena cava/superior vena cava region to avoid systemic vein obstruction.

Scimitar syndrome can be a challenging defect to treat optimally. Results can depend on timing of intervention (age at intervention), technical challenges, and potential development of baffle obstruction. ${ }^{2}$ The authors from

\footnotetext{
From the Division of Cardiothoracic Surgery, Children's Healthcare of Atlanta, Emory University School of Medicine, Atlanta, Ga.

Disclosures: The author reported no conflicts of interest.

The Journal policy requires editors and reviewers to disclose conflicts of interest and to decline handling or reviewing manuscripts for which they may have a conflict of interest. The editors and reviewers of this article have no conflicts of interest.

Received for publication Aug 5, 2020; revisions received Aug 5, 2020; accepted for publication Aug 7, 2020; available ahead of print Aug 11, 2020.

Address for reprints: Paul J. Chai, MD, Division of Cardiothoracic Surgery, Children's Healthcare of Atlanta, Emory University School of Medicine, 1405 Clifton Rd NE, Atlanta, GA 30322 (E-mail: Paul.chai@choa.org).

JTCVS Techniques 2020;4:221-2

2666-2507

Copyright (C) 2020 The Authors. Published by Elsevier Inc. on behalf of The American Association for Thoracic Surgery. This is an open access article under the CC BY-NCND license (http://creativecommons.org/licenses/by-nc-nd/4.0/).

https://doi.org/10.1016/j.xjtc.2020.08.002
}

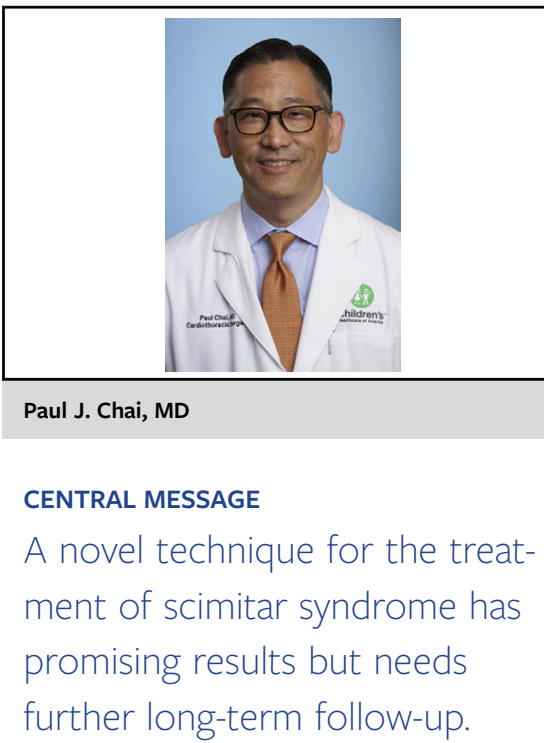

Boston should be commended on their work to attempt to improve surgical results in this difficult cohort, but after reading the manuscript and viewing Video 1 in their article, I cannot help but wonder if this is an example of "a long run for a short slide?"'

Initial results of the technique appear promising. While the follow-up time of the multipatch technique was shorter than the older technique, there was no incidence of postoperative obstruction seen using the multipatch technique. Follow-up time in the multipatch technique group was greater than 9 months in all patients (which was the period in which postoperative obstruction was observed in the older technique group).

Age is also known to be a significant factor in postoperative obstruction in these patients. Only 1 patient in the multipatch group was operated on at younger than 1 year of age. In the older-technique group, it appears as if 3 patients were operated on at younger than 1 year of age, with 2 of them having postoperative obstruction. While the postoperative results of the multipatch technique appear excellent, it may be difficult to accurately compare this group with the older-technique group, given the significant heterogeneity present in the older group.

The authors present a welcome introduction of a new technique for the treatment of scimitar syndrome where one is arguably needed. Limitations of the manuscript include relatively small numbers with a short follow-up time, which makes it impossible to fully evaluate the risk for atrial arrhythmias commonly seen in patients after Mustard/Senning or lateral tunnel Fontan procedures. ${ }^{3,4}$ It is also difficult to assess the utility of the technique in 
neonates, as there were few neonates included in the study. Nevertheless, this is one technique that deserves further observation in the future.

\section{References}

1. Geggel RL, Gauvreau K, Callahan R, Feins EN, Baird CW. Scimitar syndrome: a new multipatch technique and incidence of postoperative pulmonary vein obstruction. J Thorac Cardiovasc Surg Tech. 2020;4:208-16.
2. Dusenbery SM, Geva T, Seale A, Valente AM, Zhou J, Sena L, et al. Outcome predictors and implications for management of scimitar syndrome. Am Heart J. 2013; 165:770-7.

3. Butto F, Dunnigan A, Overholt ED, Benditt DG, Benson DW Jr. Transesophageal study of recurrent atrial tachycardia after atrial baffle procedures for complete transposition of the great arteries. Am J Cardiol. 1986;57:1356-62.

4. Rychik J, Atz AM, Celermajer DS, Deal BJ, Gatzoulis MA, Gewillig MH, et al. Evaluation and management of the child and adult with Fontan circulation: a scientific statement from the American Heart Association. Circulation. 2019;140: e234-84. 